\title{
John Rawls: breves noções de consenso sobreposto e a
}

\section{democracia deliberativa}

\author{
Roberto Alcântara de Oliveira Araújo ${ }^{1}$ \\ Flávia Moreira Guimarães Pessoa
}

\author{
"É nossa forma de usar as palavras 'democracia' \\ e 'governo democrático' que cria a maior \\ confusão. A menos que essas palavras seja \\ claramente definidas e haja concordância quanto \\ a sua definição, as pessoas vão viver numa \\ confusão inextricável de ideias, para grande \\ vantagem dos demagogos e déspotas" (Alexis de \\ Tocqueville).
}

\begin{abstract}
Resumo
Diante da carga axiológica do conceito de direito e justiça, cabe ao operador do direito encontrar referenciais teóricos sólidos que explicitem os princípios, valores e ideais que são caros a dada comunidade em suas condutas políticas e jurídicas, legitimando a própria Constituição e a ordem jurídica como um todo. Encontramos em John Rawls, mediante sua teoria da justiça como equidade e do liberalismo igualitário, o reconhecimento da existência de um pluralismo de doutrinas religiosas, filosóficas e morais na sociedade, decerto incompatíveis entre si, mas reduzíveis na revelação do consenso fundamental, capazes de convencer a sociedade, por meio de fundamentos que justifiquem as escolhas sociais. Este artigo objetiva chegar a conclusões, apontando
\end{abstract}

1 Juiz de Direito do Tribunal de Justiça do Estado Sergipe, titular da Comarca de Itabaianinha, SE. Possui graduação em Direito pelo Centro de Estudos Superiores de Maceió (2001), especialização em Direito Civil pela Sociedade de Ensino Universitário do Nordeste (2004) e em Processo pelo Centro de Estudos Superiores de Maceió (2005). Professor Convidado do Curso de especialização em Direito Civil e Processo Civil da Universidade Tiradentes - UNIT, em Aracaju, Sergipe. Atualmente exercer o cargo de Vice-Presidente Secretário Geral da Associação de Magistrados de Sergipe - AMASE, no biênio 2016/2017. Mestrando do Programa de Pós Graduação em Direito - Prodir da Universidade Federal de Sergipe - UFS. Email: alcantara.roberto@hotmail.com.

2 Possui graduação em Direito pela Universidade Federal de Sergipe (1997), mestrado em Direito pela Universidade Gama Filho (2004), doutorado em Direito Público pela Universidade Federal da Bahia e Pós Doutorado em Direito pela Universidade Federal da Bahia. É professora adjunta da Universidade Federal de Sergipe, Professora da Universidade Tiradentes, ITP e Fanese. Professora do mestrado em Direito da Universidade Federal de Sergipe, professora do Mestrado em Direitos Humanos da UNIT. Membro do Conselho Editorial da Revista Diké, do mestrado em Direito da UFS. É, ainda, juíza do trabalho - Tribunal Regional do Trabalho da 20a Região. Presidente da Associação dos Magistrados da Justiça do Trabalho da 20 Região. Atua principalmente nas áreas de Direito Constitucional, Direito Ambiental, Direito Processual Civil, Direito do Trabalho e Direito Processual do Trabalho. Membro da Academia Sergipana de Letras Jurídicas e da Academia Brasileira de Direito do Trabalho. Email: flaviampessoa@gmail.com. 
que o conceito de democracia representa mais do que a simples regra majoritária e que o Poder Público busca sua legitimidade na força argumentativa, mediante um processo justo e participativo, com o desiderato da efetividade dos direitos fundamentais e da promoção do Estado Democrático de Direito.

Palavras-chaves: Constituição. Consensos Fundamentais. Liberalismo Igualitário. Democracia Deliberativa, Legitimidade, Razão Pública.

\title{
John Rawls: brief notions of overlapping consensus and deliberative democracy.
}

\begin{abstract}
Given the axiological charge of the concept of law and justice, it is the law operator obligation to find solid theoretical frameworks that clearly define the principles, values and ideals dear to given community in its political and legal conduct, legitimating the Constitution and the law as one all. We find in John Rawls, by his theory of justice as fairness and egalitarian liberalism, the recognition of the existence of a pluralism of religious, philosophical and moral doctrines in society, indeed incompatible, but reductible in the development of fundamental consensus, able to convince society through social reasons to justify its choices. This article aims to reach conclusions, pointing out that the concept of democracy is more than the simple majority rule and that the Government seeks its legitimacy in the argumentative force through a fair and participatory process with the desideratum of the effectiveness of fundamental rights and the promotion of Democratic Law State.
\end{abstract}

Keywords: Constitution. Fundamentals Consensus. Egalitarian Liberalism. Deliberative Democracy, Legitimacy, Public Reason.

\section{INTRODUÇÃO}

Cabe ao operador do direito, na busca da melhor aplicação do direito, bem como na repercussão social da aceitação pelos destinatários das decisões e comandos contidos em suas normas, encontrar referenciais teóricos sólidos diante da grande carga axiológica do conceito de direito e justiça.

É na Constituição que encontramos os limites, fronteiras e pontos de interseção desses elementos, separando os domínios da política e do direito, da vontade e da razão, da legislação e da jurisdição ${ }^{3}$.

\footnotetext{
${ }^{3}$ BARROSO, Luís Roberto. Curso de direito constitucional contemporâneo: os conceitos fundamentais e a construção do novo mundo. 5. ed. São Paulo: Saraiva, 2015, p. 116.
} 
A noção de Constituição e de Estado Democrático de Direito está intimamente ligada a organização/estruturação do Estado e as garantias de direitos fundamentais aos cidadãos.

O princípio da legalidade constituía o critério de identificação do direito com a lei, cuja validade não dependeria de sua correspondência com a "justiça”, mas somente com a autoridade dotada de competência normativa que a produzia, objetivando a sistematicidade e plenitude ${ }^{4}$.

Tais paradigmas não resistiram aos anos e aos acontecimentos que se sucederam no século XX, resgatando a substancia da lei e os valores como o de "justiça".

Surge a necessidade de se alcançar a legitimidade da lei não só formalmente, mas a conformação substancial da norma aos valores constitucionais estabelecidos e aos direitos fundamentais.

Essa superação do positivismo jurídico, especialmente após o segundo PósGuerra e diante da ideia de supremacia da Constituição, bem como da irradiação de seu conteúdo material e axiológico por todo o ordenamento jurídico, promovendo as bandeiras do ideal liberal, como a separação dos poderes, o princípio da legalidade e a declaração dos direitos fundamentais, transforma o Estado absolutista e com poderes ilimitados por meio de restrições e limitações com o escopo de proteger os cidadãos dos arbítrios praticados 5 .

Para J.J. Gomes Canotilho, a Constituição, como norma fundamental do ordenamento jurídico, passa a exercer como principais funções: de revelação de consensos fundamentais, de legitimidade da ordem política, de garantia e de proteção, de organização do poder político e de ordem e ordenação ${ }^{6}$.

A revelação normativa do consenso fundamental da sociedade representa a explicitação dos princípios, valores e ideais que são caros a dada comunidade em suas condutas políticas e jurídicas, legitimando a própria Constituição e a ordem jurídica como um todo.

\footnotetext{
${ }^{4}$ MARINONI, Luiz Guilherme. A ética dos precedentes: justificativa do novo CPC. 2. ed. rev., atual. e ampl. São Paulo: Editora Revista dos Tribunais, 2016, p. 50.

${ }^{5}$ BARBOSA, Paulo Roberto Fonseca. O poder complementar dos juízes: instrumentos para o controle da expansão penal. Rio de Janeiro: Editora Lumen Juris, 2015, p. 186: "O ocaso da Segunda Grande Guerra desencadeou um movimento de valorização dos direitos fundamentais do indivíduo, içando o princípio da dignidade da pessoa humana a um local de destaque no campo do Direito."

${ }^{6}$ CANOTILHO, J.J. Gomes. Direito constitucional e teoria da constituição. 7. ed. Coimbra: Almedina, 2003, p. 1438.
} 
A Constituição jurídica logra conferir forma e modificar à realidade. Ela logra despertar "a força que reside na natureza das coisas", tornando-a ativa. Ela própria converte-se em força ativa que influi e determina a realidade política e social. [...] Portanto, a intensidade da força normativa da Constituição apresenta-se, em primeiro plano, como uma questão de vontade normativa, de vontade da Constituição (Wille zur Verfassung) ${ }^{7}$.

A Constituição do Estado não se contenta em ser mera declaração de direitos e pactos programáticos, posicionando-se direta e imediatamente de forma eficiente e eficaz, na concretização de seus comandos, especialmente dos direitos fundamentais ${ }^{8}$.

Além dos valores especificados nos direitos fundamentais, logo no art. $1^{\circ}$, da Constituição Federal de 1988, que institui a República Federativa do Brasil como um Estado Democrático de Direito, portanto limitado pela ordem jurídica e, em seu parágrafo único, proclama que todo poder emana do povo, exaltando a democracia ${ }^{9}$.

A eleição desses valores constitucionais, representados pela dicotomia da soberania popular e vontade da maioria versus a limitação de poder e respeito aos direitos fundamentais, conduz a relativização da distinção entre a política e o direito ${ }^{10}$.

E aqui reside o questionamento: como definir e encontrar os consensos mínimos essenciais para a comunidade e ao funcionamento do Estado Democrático de Direito?

A pesquisa realizada neste trabalho será de natureza bibliográfica/documental e descritiva. Abordará qualitativamente o tema, através de métodos racionais de argumentação e reflexão de diversas obras referentes à acepção de justiça adequada ao sistema normativo vigente, sua concepção como um valor jurídico-político, a pluralidade política, a razão pública e o consenso sobreposto, na doutrina do liberalismo igualitário proposto por John Rawls.

Ao final serão apresentadas as conclusões a que se chegar, apontando-se que o

\footnotetext{
${ }^{7}$ HESSE, Konrad. A força normativa da constituição [Tradução: Gilmar Ferreira Mendes]. Porto Alegre: Sergio Antonio Fabris Editor, 1991, p. 24.

${ }^{8}$ SAMPAIO, José Adércio Leite. Teoria da constituição e dos direitos fundamentais. Belo Horizonte: Del Rey, 2013, p. 550/556.

${ }^{9}$ BRASIL. Constituição da República Federativa do Brasil, de 08 de outubro de 1988. Brasília: Senado Federal, 1988: “Art. 1 A República Federativa do Brasil, formada pela união indissolúvel dos Estados e Municípios e do Distrito Federal, constitui-se em Estado Democrático de Direito e tem como fundamentos: I - a soberania; II - a cidadania; III - a dignidade da pessoa humana; IV - os valores sociais do trabalho e da livre iniciativa; V - o pluralismo político. Parágrafo único. Todo o poder emana do povo, que o exerce por meio de representantes eleitos ou diretamente, nos termos desta Constituição".

${ }^{10}$ GODOY, Miguel Gualano de. Constitucionalismo e democracia: uma leitura a partir de Carlos Santiago Nino e Roberto Gargarella. São Paulo: Saraiva, 2012, p. 69: “[...] enquanto a política exibe o caráter democrático das relações e a dinamicidade do seu processo, o Direito exibe a rigidez da fórmula constitucional".
} 
conceito de democracia representa mais do que a simples regra majoritária, que o Poder Público busca sua legitimidade na força argumentativa, mediante um processo justo e participativo. Tudo na busca do desiderato da efetividade dos direitos fundamentais e na promoção do Estado Democrático de Direito.

\section{DESENVOLVIMENTO}

Contemporaneamente, o direito vem permitindo uma permeabilidade aos valores éticos e políticos, despertando o debate político-constitucional de aproximação do ordenamento jurídico e a realidade social.

Desse modo, é produzida uma união necessária entre o direito, como ele é, e o direito como ele deve ser, e, como isso, entre o direito e a moral. $\mathrm{O}$ argumento principal para essa união entre direito e moral é a tese que o direito, necessariamente, promove uma pretensão de correção.

A pretensão de correção inclui uma pretensão de fundamentalidade. Isso leva ao segundo grau do argumento para o constitucionalismo discursivo ${ }^{11}$.

Historicamente, junto ao constitucionalismo surge o liberalismo como novo modelo de Estado, aproximando-se de conceitos como a democracia, estado de direito, governo da maioria e respeito aos direitos fundamentais. Inicialmente, ligado à livre iniciativa e ao livre mercado, passou, no final do século passado, por uma visão igualitária ou social democrata, agregando à noção de livre iniciativa a de intervenção estatal, na busca da distribuição igualitária de recursos e de oportunidades ${ }^{12}$.

O liberalismo igualitário teve seus fundamentos na doutrina do autor norteamericano John Rawls, com fundamento nas diretrizes de John Locke, Jean Jacques Rousseau e Immanuel Kant ${ }^{13}$, adota a concepção contratualista, elevando-a a um nível mais alto de abstração, no qual todos estariam numa "posição original", desconhecendo seu lugar na sociedade, seus dotes naturais, inteligência e força ("véu da ignorância"), definindo os princípios fundamentais de justiça daquela comunidade ${ }^{14}$.

\footnotetext{
${ }^{11}$ ALEXY, Robert. Constitucionalismo discursivo [Tradução: Luís Afonso Heck]. 4. ed. rev. Porto Alegre: Livraria do Advogado, 2015, p. 9.

12 BARROSO, Luís Roberto. Curso de direito constitucional contemporâneo: os conceitos fundamentais e a construção do novo mundo. 5. ed. São Paulo: Saraiva, 2015, p.120.

${ }^{13}$ RAWLS, John. Uma teoria da justiça [Tradução: Almiro Pisetta e Lenita M. R. Esteves]. São Paulo: Martins Fontes, 1997, p. XVII.

${ }^{14}$ GODOY, Miguel Gualano de. Constitucionalismo e democracia: uma leitura a partir de Carlos Santiago Nino e Roberto Gargarella. São Paulo: Saraiva, 2012, p. 94/95.
} 
John Rawls fundamenta sua teoria na busca da equidade e justiça social. Propõe a minimização das diferenças sociais, tais como raciais, sexuais, religiosas, culturais e econômicas para o alcance do ideal de nivelamento social.

Para Rawls, não só as leis podem ser classificadas como justas ou injustas, mas também as instituições, os sistemas sociais e as pessoas que os compõem e as que são destinatárias das normas jurídicas ${ }^{15}$.

Assim, o objetivo primário da justiça seria a estruturação da sociedade, o funcionamento das instituições sociais na busca da distribuição e afetação dos direitos e deveres entre os membros da comunidade.

Como dito, ao definir os pressupostos e modelos básicos que fundamentam a sociedade, os cidadãos, sob o "véu da ignorância", são colocados em pé de igualdade, afastando qualquer influência pessoal ou subjetiva na definição dos consensos sociais ${ }^{16}$.

É esse estado original que possibilita aos membros da sociedade definirem qual a concepção de justiça que melhor se adequa aos desideratos buscados pela e para a sociedade, inclusive, permitindo a posterior reforma, remodelação e reestruturação das instituições ${ }^{17}$.

Aqui, reside o conceito da teoria da justiça como equidade (justice as fairness), aplicável sobre as instituições básicas da sociedade com a finalidade de distribuir os benefícios e encargos sociais aos membros de dada comunidade, reparando possíveis desigualdades.

São formulados dois princípios de justiça, a saber:

Primeiro princípio. Cada pessoa deve ter um direito igual ao mais abrangente sistema total de liberdades básicas iguais que seja compatível com um sistema de liberdade para todos. Segundo princípio. As desigualdades econômicas e sociais devem ser dispostas de modo a que tanto: (a) se estabeleçam para o máximo benefício possível dos menos favorecidos que seja compatível com as restrições do princípio da poupança justa, como (b) estejam vinculadas a cargos e posições acessíveis a todos ${ }^{18}$.

\footnotetext{
${ }^{15}$ RAWLS, John. Uma teoria da justiça [Tradução: Almiro Pisetta e Lenita M. R. Esteves]. São Paulo: Martins Fontes, 1997, p. 7/9.

${ }^{16}$ RAWLS, John. Uma teoria da justiça [Tradução: Almiro Pisetta e Lenita M. R. Esteves]. São Paulo: Martins Fontes, 1997, p. 13.

${ }^{17}$ RAWLS, John. Uma teoria da justiça [Tradução: Almiro Pisetta e Lenita M. R. Esteves]. São Paulo: Martins Fontes, 1997, p. 14.

${ }^{18}$ RAWLS, John. Uma teoria da justiça [Tradução: Almiro Pisetta e Lenita M. R. Esteves]. São Paulo: Martins Fontes, 1997, p. 64.
} 
É no primeiro princípio que Rawls define as liberdades fundamentais, que devem ser iguais para todos, implicando numa estruturação de um Estado Democrático de Direito.

Já o segundo princípio de justiça deve ser visto como o princípio da igualdade equitativa de oportunidade e do princípio da diferença.

Destarte, John Rawls defende uma igualdade de oportunidades equitativas, caracterizado por uma redistribuição de condições e meios ou princípio de diferença, na qual só seriam aceitáveis as diferenciações que beneficiem aos mais desfavorecidos ${ }^{19}$.

Na filosofia de Rawls, o primeiro princípio corresponde à liberdade, enquanto o segundo corresponde à justiça distributiva. $\mathrm{O}$ próprio filósofo deixou claro que as necessidades básicas (basic needs), isto é, os mínimos sociais integram o primeiro princípio - da liberdade - e por isso são fundamentos constitucionais e não se confundem com as questões de justiça básica (basic justice $)^{20}$.

Baseado na conceito de overlapping consensus, o autor chega a conclusão que o conteúdo dos direitos e princípios fundamentais representa o conjunto de condições de cooperação social justa (consenso comum) entre os cidadãos racionais e razoáveis, marcado pelo pluralismo da sociedade.

Diante do pensamento democrático e desenvolvimento da prática constitucional é possível alcançar não apenas algum entendimento público, mas também alguma fidelidade aos ideais e valores democráticos desenvolvidos pelas instituições políticas existentes. Isto abre caminho para a elaboração da ideia do consenso sobreposto em uma concepção política da justiça: tal consenso é moral tanto em seu objeto quanto em suas bases e, assim, é distinto de um consenso - inevitavelmente frágil - baseado apenas em interesses pessoais ou de um grupo, mesmo quando descrito em uma constituição bem estruturada. A ideia do consenso sobreposto permite entender como um regime constitucional caracterizado pelo pluralismo pode, apesar de suas divergências, alcançar a estabilidade e a unidade social através do reconhecimento público de uma concepção política razoável de justiça ${ }^{21}$.

\footnotetext{
${ }^{19}$ RAWLS, John. Uma teoria da justiça [Tradução: Almiro Pisetta e Lenita M. R. Esteves]. São Paulo: Martins Fontes, 1997, p. 11/13 e 46.

${ }^{20}$ OLIVEIRA JUNIOR, Valdir Ferreira de. O estado constitucional solidarista: estratégias para sua efetivação. In MARTINS, Ives Gandra da Silva; MENDES, Gilmar Ferreira; NASCIMENTO, Carlos Valder de [coords.]. Tratado de direito constitucional, v. 1. 2.ed. São Paulo: Saraiva, 2012, p. 235.

${ }^{21}$ RAWLS, John. The idea of an overlapping consensus. Oxford University Press, 1987. Disponível em: <http://www.jstor.org/stable/764257>. Acesso em 09 abr. 2013, 19:29:00, p. 2.
} 

ANÁLISE DA DECISÃO SOBRE UNIÃO HOMOAFETIVA

Rawls ressalta que tais juízos e valores de justiça não são imutáveis, havendo espaço para revisões conceituais indispensáveis ${ }^{22}$.

Sua lição reconhece a existência um pluralismo de doutrinas religiosas, filosóficas e morais abrangentes, decerto incompatíveis entre si. Para tanto, acredita na possibilidade de criação de razões de justificação pública razoável no tocante a questões políticas fundamentais.

Novamente fazendo um paralelo com a Constituição Federal brasileira de 1988, verifica-se que o reconhecimento do pluralismo no artigo $1^{\circ}$, inciso $\mathrm{V}$, in verbis: "Art. $1^{o}$ A República Federativa do Brasil, formada pela união indissolúvel dos Estados e Municípios e do Distrito Federal, constitui-se em Estado Democrático de Direito e tem como fundamentos: [...] V - o pluralismo politico" ${ }^{\text {23 }}$.

Nem todas as razões são razões públicas, pois temos as razões não-públicas de igrejas, universidades e de muitas outras associações da sociedade civil. Em regimes aristocráticos e autocráticos, quando o bem da sociedade é considerado, isso não é feito pelo público, se é que ele existe, mas pelos governantes, sejam quem forem. A razão pública é característica de um povo democrático: é a razão de seus cidadãos, daqueles que compartilham o status da cidadania igual. O objeto dessa razão é o bem do público: aquilo que a concepção política de justiça requer da estrutura básica das instituições da sociedade e dos objetivos e fins a que devem servir. Portanto, a razão pública é pública em três sentidos: enquanto a razão dos cidadãos como tais, é a razão do público; seu objeto é o bem do público e as questões de justiça fundamental; e sua natureza e conceito são públicos, sendo determinados pelos ideais e princípios expressos pela concepção de justiça política da sociedade e conduzidos à vista de todos sobre essa base ${ }^{24}$.

Destarte, a função da razão pública é permitir que os princípios de justiça possam ser justificados perante todos os cidadãos e aplicados corretamente, estabelecendo-se uma relação necessária entre justiça e democracia ${ }^{25}$.

A razão pública é um padrão de argumentação moral que deve disciplinar a deliberação política, mas que não se confunde com ela, e, portanto, subsiste enquanto critério autônomo para julgar a legitimidade das decisões ${ }^{26}$.

\footnotetext{
${ }^{22}$ RAWLS, John. Uma teoria da justiça [Tradução: Almiro Pisetta e Lenita M. R. Esteves]. São Paulo: Martins Fontes, 1997, p. 23.

${ }^{23}$ BRASIL. Constituição da República Federativa do Brasil, de 08 de outubro de 1988. Brasília: Senado Federal, 1988.

${ }^{24}$ RAWLS, John. O liberalismo político [Tradução: Dinah de Abreu Azevedo]. 2. ed. São Paulo: Editora Ática, 2000, p. 267/268.

${ }^{25}$ RAWLS, John. O liberalismo político [Tradução: Dinah de Abreu Azevedo]. 2. ed. São Paulo: Editora Ática, 2000, p. 273.

${ }^{26}$ MENDES, Conrado Hübner. Direitos fundamentais, separação de poderes e deliberação. São Paulo: Saraiva, 2011, p. 492.
} 
Jürgen Habermas não concorda com Rawls ao não limitar a sua análise da democracia à esfera da filosofia política, discordando quanto à forma e ao conteúdo da concepção de democracia, ampliando sua análise para esferas como a teoria social e a filosofia da linguagem, criando, assim, uma ética do discurso. Habermas assente que a teoria da Justiça de Rawls foi um marco na história da filosofia prática. Para o autor, a obra de Rawls retomou questões morais essenciais que estavam relegadas há muito tempo 27 .

Habermas se preocupa em erigir, em sua ética do discurso, um contexto ideal de comunicação capaz de incluir, em condições de igualdade e liberdade, todos os participantes do processo comunicativo. Para tanto, apresenta a esfera pública como o espaço privilegiado em que as normas emergentes do mundo da vida são racionalizadas pela comunicação para então poderem, por meio do processo decisório, ter espaço no âmbito estatal. Enquanto Rawls estabelece um modelo substantivo de democracia deliberativa (na qual os princípios a serem aplicados já estão previamente justificados), Habermas, ao contrário, elabora um modelo fortemente procedimental de democracia deliberativa. $\mathrm{O}$ modelo de Habermas é procedimental porque deixa em aberto os possíveis resultados da deliberação. Vale dizer, os princípios a serem aplicados devem encontrar a sua justificação no curso do próprio processo deliberativo. Daí a ideia de que as maiorias estão impedidas de tomar decisões que obstaculizem a realização das condições procedimentais da própria democracia ${ }^{28}$.

$\mathrm{Na}$ concepção comum e significado etimológico, democracia resume-se no poder do povo, exercido de forma direta ou por meio de representantes eleitos.

Essa concepção formal ou procedimental representa elemento indissociável da essência do conceito de democracia, mas, na atual quadra histórica, não se mostra suficiente para a definição de um sistema político como democrático, em especial como uma democracia constitucional, na qual nos deparamos com a fixação de limites e conteúdos substanciais definidos pelos direitos fundamentais em face do exercício dos poderes dos Estado.

Portanto, a noção de democracia constitucional não se satisfaz apenas com a legitimação pelo voto da maioria, exigindo também a efetividade de conteúdos materiais mínimos, tais como a realização dos direitos fundamentais mediante o

27 GODOY, Miguel Gualano de. Constitucionalismo e democracia: uma leitura a partir de Carlos Santiago Nino e Roberto Gargarella. São Paulo: Saraiva, 2012, p. 101/102.

${ }^{28}$ GODOY, Miguel Gualano de. Constitucionalismo e democracia: uma leitura a partir de Carlos Santiago Nino e Roberto Gargarella. São Paulo: Saraiva, 2012, p. 101/102. 

ANÁLISE DA DECISÃO SOBRE UNIÃO HOMOAFETIVA

respeito aos limites negativos (liberdades públicas) e as concretizações das prestações positivas (demandas sociais) $)^{29}$.

O cerne da legitimidade da teoria do liberalismo de John Rawls está na força da argumentação e do discurso. A argumentação adequada e capaz de convencer a sociedade, por meio de fundamentos que justifiquem as escolhas Estatais.

O Ministro do Supremo Tribunal Federal Luís Roberto Barroso: “o constitucionalismo democrático se funda na institucionalização da razão e da correção moral ${ }^{, 30}$.

Essa democracia discursiva e argumentativa, como forma de legitimar a realização dos direitos fundamentais, recebeu de Robert Alexy o nome de democracia deliberativa, na qual os agentes e instituições públicas devem fundamentar suas decisões em bons argumentos ou argumentos plausíveis, visando o convencimento racional da sociedade ${ }^{31}$.

A deliberação pressupõe uma concepção dialógica da política e a consideração desta como um processo racional de discussão dos problemas e alternativas, de forma a obterem-se soluções justa, boas, ou, pelo menos, razoáveis, de ordenação da vida comunitária. A política serve para deliberar sobre a ordenação comunitária e não apenas para fornecer aberturas processuais à prossecução de interesses privados ou à optimização de preferências subjetivas ${ }^{32}$.

\footnotetext{
${ }^{29}$ BARROSO, Luís Roberto. O controle de constitucionalidade no direito brasileiro : exposição sistemática da doutrina e análise crítica da jurisprudência. 6. ed. rev. e atual. - São Paulo: Saraiva, 2012, p. 100: "A democracia não se assenta apenas no princípio majoritário, mas, também, na realização de valores substantivos, na concretização dos direitos fundamentais e na observância de procedimentos que assegurem a participação livre e igualitária de todas as pessoas nos processos decisórios. A tutela desses valores, direitos e procedimentos é o fundamento de legitimidade da jurisdição constitucional. Partindo dessas premissas, parece plenamente possível conciliar democracia e jurisdição constitucional, quer se defenda uma noção procedimental de Constituição — que privilegia a definição das regras do jogo político, cuja observância legitimaria os resultados produzidos —, quer se opte por um modelo substancialista - no qual certas opções materiais já estariam predefinidas".

${ }^{30}$ BARROSO, Luís Roberto. Curso de direito constitucional contemporâneo: os conceitos fundamentais e a construção do novo mundo. 5. ed. São Paulo: Saraiva, 2015, p. 477.

${ }^{31}$ A inclusão da argumentação no conceito de democracia faz desta uma democracia deliberativa, a qual nada mais é do que uma tentativa de institucionalizar, tanto quanto possível, o discurso que defende a tomada pública de decisões. Por este motivo, a conexão entre a sociedade e o parlamento não pode ser determinada apenas pelas decisões expressas nas eleições e nos votos, mas também pela argumentação. Neste sentido, a representatividade da sociedade pelo Parlamento é, a um só tempo, volitiva ou decisiva, assim como argumentativa ou discursiva (ALEXY, Robert. Balancing, constitutional review and representation. Oxford University Press, 2005. Disponível em: <http://icon.oxfordjournals.org/content/3/4/572.full.pdf>. Acesso em 05 jun. 2016, 16:38:00, p. 579).

${ }^{32}$ CANOTILHO, J.J. Gomes. Direito constitucional e teoria da constituição. 7. ed. Coimbra: Almedina, 2003, p. 1416.
} 
Esse é o modelo democrático que vivemos, no qual o Poder Público encontra sua fundamentação mediante um processo que apresente um procedimento aberto à participação efetiva, com atos públicos e decisões fundamentadas em argumentos convincentes e que apresente como desiderato a tutela dos direitos fundamentais e aos consensos sociais.

Não é preciso dizer que a tarefa de conferir significado a um direito fundamental é algo que está muito longe do raciocínio judicial moldado pelos esquemas do positivismo clássico - interpretação cognitivista de uma norma pré-existente dada exclusivamente pelo legislador e aplicação logicista da norma - pois revela a necessidade de consideração de fatores que devem ser observados e compreendidos em outras perspectivas, como a moral e a econômica ${ }^{33}$.

John Rawls objetiva estruturar o processo democrático e estabelecer princípios substantivos que expressem um resultado do processo justo.

A lei, sonhada como o porto seguro de chegada, tornou-se um obrigatório ponto inicial de dúvidas e incertezas. Esquecer esta verdade - que o direito dos tribunais, na experiência contemporânea, nos ensina a cada dia - será o caminho que nos sujeitará à condição de vítimas das mais variadas formas de arbitrariedades, cometidas em nome do que se imagina ser a imparcial aplicação da "vontade da lei", em sentenças que, antes de alicerçarem-se em fundamentos válidos, ocultam as verdadeiras razões de decidir.

Nosso mundo tornou-se demasiadamente hermenêutico. [...] A razão é simples. A Democracia pressupõe tolerância. Não pode haver regime democrático quando exigimos que nossos interesses e valores sejam aceitos como absolutos; não haverá democracia se formos incapazes de conviver com a diversidade, com valores do "outro" 34 .

Essa restruturação gerou uma crise de legitimidade do discurso normativo fundada na forma de tratamento do direito positivo aos fatos, quando "passou a oferecer respostas formalmente adequadas com o sistema vigente, mas incompatíveis com valores sociais que se tornavam dominantes "35.

Tal crise seria desvelada pela inefetividade da Constituição, a crise da justiça, a morosidade e o problema do acesso à justiça, a não-implementação dos direitos sociais... Ou seja, o cotejamento entre o texto constitucional e a realidade social.

\footnotetext{
${ }^{33}$ MARINONI, Luiz Guilherme. A ética dos precedentes: justificativa do novo CPC. 2. ed. rev., atual. e ampl. São Paulo: Editora Revista dos Tribunais, 2016, p. 56

${ }^{34}$ SILVA, Ovídio A. Baptista da. Jurisdição, direito material e processo. Rio de Janeiro: Forense, 2008, p. 140/141.

${ }^{35}$ COSTA, Alexandre Araújo. Direito e método: diálogos entre a hermenêutica filosófica e a hermenêutica jurídica [Tese de doutorado]. Brasília: UNB, 2010. Disponível em: <http://dominiopublico.mec.gov.br/download/teste/arqs/cp149009.pdf〉. Acesso em 28 de setembro de 2016, 08:45:00, p. 284.
} 
O Lenio Luiz Steck mostra-se “convencido que há uma crise de paradigmas que obstaculiza a realização (o acontecer) da Constituição (e, portanto, dos objetivos da justiça social, da igualdade, da função social da propriedade, etc.)” 36.

Tal crise restou superada com a passagem do Estado Liberal para o Estado Social, mediante a utilização do discurso hermenêutico, no qual era possível modificar judicialmente o sentido da norma sem alterar o texto legal.

Essa abertura possibilitou a politização do discurso jurídico, modificando a interpretação do direito, mas mantendo parâmetros objetivos. Não houve uma rejeição absoluta do normativismo, mas uma mitigação da argumentação puramente deontológica.

Como se vê, esse ambiente de normatividade dos princípios e concretização dos consensos fundamentais, da interpretação e argumentação jurídicas, inaugurado no Brasil com a Constituição Federal de 1988, tem como marco filosófico o pós positivismo $^{37}$ e transpassa todo o ordenamento jurídico pátrio, que deve ser visto mediante o prisma do neoconstitucionalismo ${ }^{38}$.

\section{CONCLUSÃO}

As conclusões do presente artigo foram apresentadas ao longo do texto, mas cabe buscar sintetiza-las nesse espaço.

O Estado Democrático de Direito exibe como principais características o respeito a democracia e a dignidade da pessoa humana e a necessária efetivação dos direitos e garantias fundamentais, apresentados nos princípios e valores constitucionalmente definidos.

\footnotetext{
${ }^{36}$ STRECK, Lenio Luiz. Jurisdição constitucional e hermenêutica: uma nova crítica do direito. Porto Alegre: Livraria do Advogado, 2002, p. 187.

${ }^{37}$ RAWLS, John. Uma teoria da justiça [Tradução: Almiro Pisetta e Lenita M. R. Esteves]. São Paulo: Martins Fontes, 1997.

${ }^{38}$ VELOSO, Carlos Mário da Silva. Da jurisdição constitucional ou do controle de constitucionalidade. In MARTINS, Ives Gandra da Silva; MENDES, Gilmar Ferreira; NASCIMENTO, Carlos Valder de [coords.]. Tratado de direito constitucional, v. 1. 2.ed. São Paulo: Saraiva, 2012, p. 897/898: “[...] o Direito não pode ser compreendido sem a ética e com a introdução de meios de interpretação capazes de captar e ressaltar valores, a interpretação inspirada numa teoria de justiça, o direito interpretado a partir do princípio da dignidade humana; finalmente, o marco teórico, com o reconhecimento da força normativa da Constituição, a expansão da jurisdição constitucional e o desenvolvimento de hermenêutica constitucional inovadora."
} 
Tais valores constitucionais têm o desiderato de possibilitar as respostas as variadas e crescentes demandas sociais e a efetividade da própria sociedade e da força normativa de suas disposições.

A compreensão do conceito de democracia não pode ser restringido a técnica da vontade da maioria. Exige que o ordenamento jurídico corresponda aos anseios sociais, definidos por meio de consensos.

Exige a participação de todos os cidadãos nos processos decisórios do poder público; o respeito a liberdade e igualdade de cada um dos membros da sociedade; a tolerância com a pluralidade de ideias e a vontade da minoria. Mas, sobretudo, a garantia dos direitos fundamentais encartados na Constituição da República.

A teoria da justiça de John Rawls reconcilia a liberdade e igualdade dos cidadãos que compõem o grupo social, por meio da aplicação dos princípios de justiça que devem ser fundamentados segundo um procedimento participativo e plural, objetivando estruturar o processo democrático e estabelecer princípios substantivos que expressem um resultado do processo justo.

Ao serem constitucionalmente definidos seus consensos, a sociedade deposita a consecução de concretizar as prerrogativas e direitos fundamentais dos indivíduos ao Estado, na busca da não discriminação e a fim de facilitar a integração dos grupos minoritários no meio social - teoria da justiça como equidade (justice as fairness).

Assim, o Poder Estatal retira sua legitimidade da discussão racional travada por meio de mecanismos, concebidos através de procedimento em contraditório e participativo, que conclua com uma decisão fundamentada que efetive a tutela dos direitos fundamentais previstos à espécie e dos consensos sociais estabelecidos na Carta Magna, por meio de todos os seus órgãos, seja no exercício da função legislativa, executiva ou jurisdicional.

Atender aos preceitos de participação e diálogo democráticos confere mais que legitimidade ao Estado Democrático de Direito, atende à necessidade de efetivo controle e fiscalização, racionalidade e segurança jurídica, oferecendo à sociedade valores e fins justos e équos.

\section{REFERÊNCIAS}


ALEXY, Robert. Balancing, constitutional review and representation. Oxford University $2005 . \quad$ Press, Disponível em: <http://icon.oxfordjournals.org/content/3/4/572.full.pdf>. Acesso em 05 jun. 2016, 16:38:00.

Constitucionalismo discursivo [Tradução: Luís Afonso Heck]. 4. ed. rev. Porto Alegre: Livraria do Advogado, 2015.

BARBOSA, Paulo Roberto Fonseca. O poder complementar dos juízes: instrumentos para o controle da expansão penal. Rio de Janeiro: Editora Lumen Juris, 2015.

BARROSO, Luís Roberto. Curso de direito constitucional contemporâneo: os conceitos fundamentais e a construção do novo mundo. 5. ed. São Paulo: Saraiva, 2015.

O controle de constitucionalidade no direito brasileiro : exposição sistemática da doutrina e análise crítica da jurisprudência. 6. ed. rev. e atual. São Paulo: Saraiva, 2012.

BRASIL. Constituição da República Federativa do Brasil, de 08 de outubro de 1988. Brasília: Senado Federal, 1988.

CANOTILHO, J.J. Gomes. Direito constitucional e teoria da constituição. 7. ed. Coimbra: Almedina, 2003.

COSTA, Alexandre Araújo. Direito e método: diálogos entre a hermenêutica filosófica e a hermenêutica jurídica [Tese de doutorado]. Brasília: UNB, 2010.

Disponível em: <http://dominiopublico.mec.gov.br/download/teste/arqs/cp149009.pdf〉. Acesso em 28 de setembro de 2016, 08:45:00.

GODOY, Miguel Gualano de. Constitucionalismo e democracia: uma leitura a partir de Carlos Santiago Nino e Roberto Gargarella. São Paulo: Saraiva, 2012. HESSE, Konrad. A força normativa da constituição [Tradução: Gilmar Ferreira Mendes]. Porto Alegre: Sergio Antonio Fabris Editor, 1991. 
MARINONI, Luiz Guilherme. A ética dos precedentes: justificativa do novo CPC.

2. ed. rev., atual. e ampl. São Paulo: Editora Revista dos Tribunais, 2016.

MENDES, Conrado Hübner. Direitos fundamentais, separação de poderes e deliberação. São Paulo: Saraiva, 2011.

OLIVEIRA JUNIOR, Valdir Ferreira de. O estado constitucional solidarista: estratégias para sua efetivação. In MARTINS, Ives Gandra da Silva; MENDES, Gilmar Ferreira; NASCIMENTO, Carlos Valder de [coords.]. Tratado de direito constitucional, v. 1. 2.ed. São Paulo: Saraiva, 2012.

RAWLS, John. Uma teoria da justiça [Tradução: Almiro Pisetta e Lenita M. R. Esteves]. São Paulo: Martins Fontes, 1997.

O liberalismo político [Tradução: Dinah de Abreu Azevedo]. 2. ed. São Paulo: Editora Ática, 2000.

The idea of an overlapping consensus. Oxford University Press, 1987.

Disponível em: <http://www.jstor.org/stable/764257>. Acesso em 09 abr. 2013, 19:29:00.

SAMPAIO, José Adércio Leite. Teoria da constituição e dos direitos fundamentais. Belo Horizonte: Del Rey, 2013.

STRECK, Lenio Luiz. Jurisdição constitucional e hermenêutica: uma nova crítica do direito. Porto Alegre: Livraria do Advogado, 2002.

VELOSO, Carlos Mário da Silva. Da jurisdição constitucional ou do controle de constitucionalidade. In MARTINS, Ives Gandra da Silva; MENDES, Gilmar Ferreira; NASCIMENTO, Carlos Valder de [coords.]. Tratado de direito constitucional, v. 1. 2.ed. São Paulo: Saraiva, 2012. 